\title{
The Influence of Sterols on Meiosis in Phytophthora cactorum
}

\author{
By C. G. ELLIOTT \\ Department of Botany, The University of Glasgow, Glasgow GI2 $8 Q Q$ \\ AND EVA SANSOME \\ 6 Roydon Road, Diss, Norfolk IP22 $32 N$
}

(Received 24 June 1976)

\begin{abstract}
SUMMAR Y
Abortion of oogonia of Phytophthora cactorum grown on media containing cholestanol occurs at or just before early meiotic prophase. Meiosis is possibly controlled by a steroid hormone, for which cholesterol is an effective precursor but cholestanol is not.
\end{abstract}

\section{INTRODUCTION}

Phytophthora cactorum grows vegetatively on a simple medium containing sucrose, asparagine, mineral salts and thiamin, but sterols need to be added to induce development of sexual stages, namely antheridia and oogonia, and of the oospores formed inside the oogonia. Cholesterol (5-cholesten-3 $\beta$-ol) and cholestanol ( $5 \alpha$-cholestan-3 $\beta$-ol) both promote vegetative growth and support the development of oogonia and antheridia equally well. However, while many oospores are produced in cultures containing cholesterol, very few of the oogonia produced in the presence of cholestanol develop oospores; most of them degenerate (Elliott, 1968, 1972). Similar abortion of oogonia in cultures with cholestanol has been observed in Pythium periplocum and Pythium prolatum (Hendrix \& Guttmann, 1972) and in Phytophthora drechsleri (G. A. Bean \& C. G. Elliott, unpublished).

Cytological observations (Sansome, 1961, 1965; Sansome \& Brasier, 1973; Brasier \& Sansome, 1975; Mortimer \& Shaw, 1975) indicate that meiosis occurs in the antheridia and oogonia of these fungi and this interpretation is supported by genetical data for $P$. cactorum (Elliott \& MacIntyre, I973) and $P$. drechsleri (Shaw \& Khaki, 1971; Khaki \& Shaw, 1974). It seemed important to determine whether the abortion of oogonia observed with cholestanol occurred before, during or after meiosis. Observations on this point in P. cactorum are the subject of this paper.

\section{METHODS}

Phytophthora cactorum was grown at $25^{\circ} \mathrm{C}$ in $100 \mathrm{ml}$ conical flasks containing $10 \mathrm{ml}$ liquid basal medium (Elliott, Hendrie \& Knights, I966) plus $\mathrm{CaCl}_{2}$ (0. I $\mathrm{g} \mathrm{l}^{-1}$ ). Four days after inoculation of the sterol-free medium, $100 \mu \mathrm{g}$ cholesterol or cholestanol, dissolved in $\mathrm{I} \mathrm{ml}$ of $\mathrm{I} \%(\mathrm{v} / \mathrm{v})$ aqueous solution of Tween 80 , was added to each flask. Mycelium was harvested on three successive days as oogonia appeared and matured. The mycelium was chilled at $4{ }^{\circ} \mathrm{C}$ for $2 \mathrm{~h}$, fixed in acetic acid/ethanol $(\mathrm{I}: 3, \mathrm{v} / \mathrm{v})$, and then transferred to diethyl ether/ethanol ( $\mathrm{I}: \mathrm{I}, \mathrm{v} / \mathrm{v}$ ) for $24 \mathrm{~h}$ before storage in $70 \%(\mathrm{v} / \mathrm{v})$ ethanol. Aceto-orcein and aceto-carmine squash preparations were made after the material had been washed in water and treated with $\mathrm{I} \%(\mathrm{w} / \mathrm{v})$ citric acid for $\mathrm{I} 0 \mathrm{~min}$. Using aceto-orcein, the material was left in varying concentrations of orcein in $60 \%$ acetic acid for $4 \mathrm{~h}$ or longer in a covered dish. 

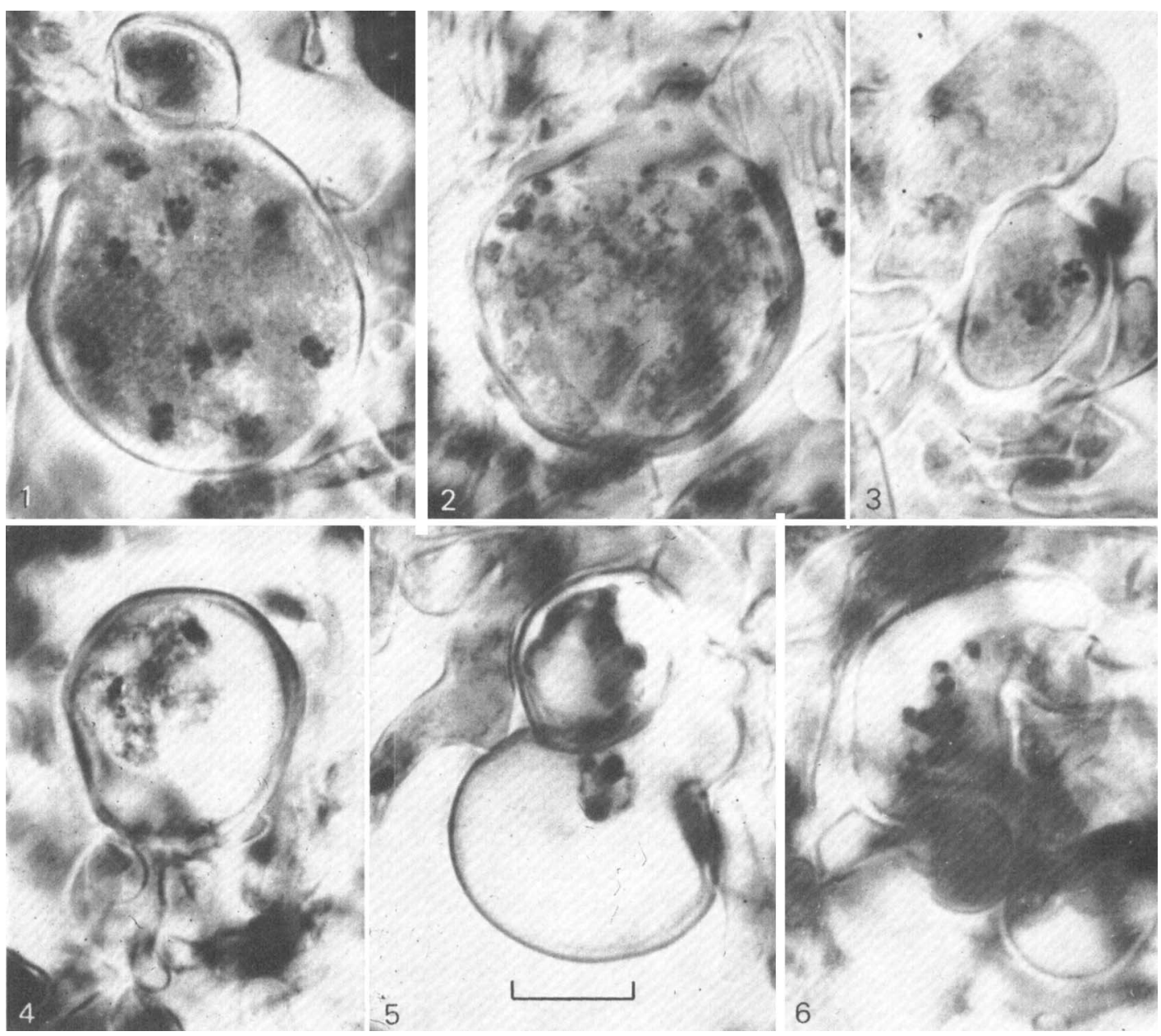

Figs $\mathrm{I}$ and 2 from cholesterol-grown cultures. Figs 3 to 6 from cholestanol-grown cultures. Bar marker represents Io $\mu \mathrm{m}$.

Fig. $x$. Metaphase $\mathrm{I}$ in oogonium, prophase in adjacent antheridium.

Fig. 2. Oosphere and haploid periplasm nuclei.

Fig. 3. Metaphase I in small oogonium. Overlying antheridium, out of focus, to the right and part of an adjacent aborting oogonium above.

Fig. 4. Aborting oogonium with two undivided nuclei and disintegrating cytoplasm.

Fig. 5. Oogonium at later stage of abortion with less cytoplasm and two aborting nuclei.

Fig. 6. Oogonium aborting after meiosis, with haploid nuclei.

For aceto-carmine squashes, the material was placed in aceto-carmine to which a drop of ferric acetate in $45 \%$ acetic acid was added, and samples were removed after $10 \mathrm{~min}$. The illustrations are of aceto-carmine preparations, which were the clearest.

Supplementary observations were made on cultures in medium solidified with $\mathrm{I} \%(\mathrm{w} / \mathrm{v})$ agar. Cholesterol or cholestanol were dissolved in ether and added to the autoclaved basal medium before it was poured into Petri dishes $(5 \mathrm{~cm})$; the sterol concentration was $4 \mu \mathrm{g} \mathrm{ml}^{-1}$. Small blocks of agar were cut from near the edges of several Petri dishes and squashed under coverslips, without fixation or staining. 
Table I. Abortion of oogonia of P. cactorum grown in liquid media supplemented with cholesterol or cholestanol

$\begin{array}{lcccccc}\text { Empty } & & \text { Aborting oogonia } & & \\ \text { oogonia* } & \begin{array}{c}\text { Before } \\ \text { meiosis }\end{array} & \begin{array}{c}\text { After } \\ \text { meiosis }\end{array} & \begin{array}{c}\text { Early and } \\ \text { developing } \dagger\end{array} & \text { Oospores } & \text { Total } \\ \text { Cholesterol } & 42 & 53 & 19 & 346 & 313 & 773 \\ \text { Cholestanol } & 119 & 224 & 0 & 77 & 6 & 426\end{array}$

* Since there was a considerable range in size of oogonia, it was not always possible to distinguish these from empty antheridia. Empty oogonia were scored only when the adjacent antheridia could be recognized.

$\dagger$ It was not possible to distinguish early meiotic stages from stages prior to meiosis.

\section{RESULTS}

The development of oogonia and antheridia in cultures grown with cholesterol or cholestanol was indistinguishable in the early stages. In the material grown on cholesterolsupplemented medium, most of the gametangia developed in the way typical of Oomycetes; some of the nuclei aborted, the remainder enlarged and entered the first meiotic prophase, followed by metaphase I (Fig. I), anaphase I and a rapid second division. This resulted in the production of smaller haploid nuclei (Fig. 2).

Meiotic stages were only rarely observed in the material grown on cholestanol-supplemented medium. Most frequently, after the earliest stages, the antheridia and oogonia were observed to be in various stages of disintegration (Figs 4 and 5). The cytoplasm became much less dense and possibly disappeared more rapidly than the nuclei. The sizes of the nuclei in aborting antheridia and oogonia were usually approximately the same as those in vegetative hyphae. Evidently, at about the stage at which the nuclei should enlarge and enter prophase, a process of disintegration begins and proceeds very rapidly.

In a few exceptional cases meiotic stages were observed in cholestanol-grown cultures. Metaphase $I$ in a small oogonium is illustrated in Fig. 3. In gametangia with nuclei undergoing meiosis, all the nuclei were at approximately the same stage, none were aborting. One case was observed (Fig. 6) in which meiosis had occurred as indicated by the size and number of nuclei, but oosphere formation had not taken place.

The frequency of aborted oogonia was estimated in 4-week-old agar cultures. In cholesterolgrown cultures, I6I oogonia with oospores and 248 aborted were counted (60.6\% abortion). There were significant differences between dishes, the counts ranging from 48 to $86 \%$ aborted. This difference in abortion would be one factor contributing to the significant variation between dishes in the number of oospores observed (Elliott, 1968, 1972). For cholestanol, the counts were 3 oogonia with oospores and 374 aborted ( $99.2 \%$ abortion).

Abortion was also estimated in stained preparations made from the liquid cultures. From the results (Table I), sterility may be estimated in two ways. The intermediate stages may be ignored, and the proportions of empty oogonia to oogonia with oospores considered. These are $42: 3^{1} 3$ in the cholesterol series, representing II.9\% abortion, and II $9: 6$ or $95.2 \%$ abortion in the cholestanol series. Alternatively, the intermediate stages can be taken into account so as to give upper and lower limits. Thus the numbers of aborting oogonia can be added to the empty oogonia, and the early and developing stages can be added either to the empty oogonia to give the upper limit of abortion, or to the oospores to give the lower limit. In the cholesterol series this would give a ratio of $460: 313(59.5 \%)$ as the upper limit of abortion and II $4: 659$ (I4.8\%) as the lower limit. In the cholestanol series the upper 
limit would be $420: 6(98 \cdot 2 \%)$ and the lower limit $343: 83(80.5 \%)$. The values for the cholesterol series are much lower than those found in the agar cultures, but besides the solid/liquid difference, the sterol concentration was different and there was no Tween 80 in the agar cultures.

There are three main factors causing abortion: environment, segregation of lethals, and the difference between cholestanol and cholesterol. Variation between dishes in the incidence of abortion is an environmental effect. In occasional patches of mycelium all the oogonia were empty, and in the preparations made from the liquid cultures these were not recorded as it was thought such abortion could only be due to environmental causes. Abortion, possibly due to segregation of lethal combinations of genetic factors, is suggested in the case of the 19 out of 72 aborting oogonia scored in the cholesterol-grown material which had apparently haploid nuclei. The frequency of abortion due to genetic segregation (both gametic and zygotic) may be estimated from the proportions $19: 313(5.7 \%)$ as a lower limit or $19+(42 \times 19 / 72): 313(8.6 \%)$ as an upper limit. No aborting oogonia with apparently haploid nuclei were observed in the recorded samples of the cholestanol cultures, but one was observed in a more extensive examination (Fig. 6).

\section{DISCUSSION}

We have shown that in Phytophthora cactorum grown with cholestanol, the majority of oogonia degenerate at or just before early meiotic prophase. Since very few meiotic stages were observed and since a few oospores were formed with cholestanol, it appears that there is a critical stage during which abortion occurs. If the gametangia survive this critical stage and enter meiosis, they are able to proceed to oospore formation. Since all the nuclei in a gametangium behave in the same way, the effect is a general one on the sex organ as a whole and not an effect on individual nuclei. One of the earliest effects is that the cytoplasm becomes less dense. This suggests that an electron microscope study of the cytoplasmic elements might be instructive.

The physiological activity of sterols may be a result of their function as constituents of membranes or as precursors of hormones (Heftmann, 197I). In their function as constituents of membranes there seems to be little difference between cholesterol and cholestanol. This is shown both by work with artificial membranes (e.g. Demel, Bruckdorfer \& Van Deenen, I972a,b) and erythrocytes (Bruckdorfer et al., 1969), and by their effect in promoting growth of mycoplasma (Smith \& Lynn, 1958; Smith, 1964; Rottem, Pfendt \& Hayflick, I97I). There is no significant difference in the growth rate of $P$. cactorum grown with the two sterols, measured either as colony diameter or as weight of mycelium (Elliott et al., 1966; Elliott, 1968). It is conceivable that the oosphere membrane might have special properties which are defective when it contains cholestanol rather than cholesterol, but in that case one would hardly expect degeneration to occur at the beginning of meiosis, before oosphere delimitation.

Reproduction in Achlya is controlled by steroid hormones. Antheridiol (McMorris \& Barksdale, 1967; Arsenault et al., 1968), derived biosynthetically from fucosterol (Popplestone \& Unrau, I974), induces formation of antheridial branches and antheridia. Oogoniol (McMorris et al., 1975) induces formation of oogonia. In addition, Raper (I940) postulated a hormone D which was responsible for the delimitation of oospheres. Barksdale (I960) has described certain matings in Achlya which fail at the oosphere-delimitation stage and it is possible that these matings are defective in the functioning of the delimiting hormone.

We believe that the similarities in reproductive pattern observed throughout the Oomycetes 
and characteristic of this class of fungi indicate that all Oomycetes share a similar control mechanism. We suggest that in Phytophthora there is a delimiting hormone, the function of which is to control meiosis, and that cholesterol is an effective precursor for this hormone, but cholestanol is not.

\section{REFERENCES}

Arsenault, G. P., Biemann, K., Barksdale, A. W. \& McMorris, 'T. C. (I968). The structure of antheridiol, a sex hormone in Achlya bisexualis. Journal of the American Chemical Society 9o, 5635-5636.

Barksdale, A. W. (I960). Interthallic sexual reactions in Achlya, a genus of aquatic fungi. American Journal of Botany 47, 14-23.

Brasier, C. M. \& SANSOMe, E. (1975). Diploidy and gametangial meiosis in Phytophthora cinnamomi, $P$. infestans and P. drechsleri. Transactions of the British Mycological Society 65, 49-65.

Bruckdorfer, K. R., Demel, R. A., De Gier, J. \& VAN Deenen, L. L. M. (I969). The effect of partial replacement of membrane cholesterol by other sterols on the osmotic fragility and glycerol permeability of erythrocytes. Biochimica et biophysica acta $\mathbf{1 8 3}, 334-345$.

Demel, R. A., Bruckdorfer, K. R. \& VAN DeEnEN, L. L. M. (1972a). Structural requirements of sterols for the interaction with lecithin at the air-water interface. Biochimica et biophysica acta 255, 3I I-320.

Demel, R. A., Bruckdorfer, K. R. \& VAN Deenen, L. L. M. (1972 $b$ ). The effect of sterol structure on the permeability of liposomes to glucose, glycerol and $\mathrm{Rb}^{+}$. Biochimica et biophysica acta $255,32 \mathrm{I}-330$.

ElliotT, C. G. (1968). Competition and synergism between cholesterol and cholestanol in oospore formation in Phytophthora cactorum. Journal of General Microbiology 51, 137-143.

ElliotT, C. G. (1972). Sterols and the production of oospores by Phytophthora cactorum. Journal of General Microbiology 72, $32 \mathrm{I}-327$.

Elliott, C. G. \& MAcInTYRE, D. (1973). Genetical evidence on the life-history of Phytophthora. Transactions of the British Mycological Society 60, 31 1-316.

Elliott, C. G., Hendrie, M. R. \& KNights, B. A. (1966). The sterol requirement of Phytophthora cactorum. Journal of General Microbiology 42, 425-435.

Heftmann, E. (1971). The functions of sterols in plants. Lipids 6, 128-133.

Hendrix, J. W. \& Guttmann, S. M. (1972). Steroid structure in relation to induction and inhibition of oospore formation in Pythium periplocum and P. prolatum. Phytopathology 62, 763 .

KHAKI, I. A. \& SHAw, D. S. (I974). The inheritance of drug resistance and compatibility type in Phytophthora drechsleri. Genetical Research 23, 75-86.

MCMorris, T. C. \& Barksdale, A. W. (1967). Isolation of a sex hormone from the water mould Achlya bisexualis. Nature, London 215, 320-32I.

McMorris, T. C., Seshadri, R., Wethe, G. R., Arsenault, G. P. \& Barksdale, A. W. (i975). Structures of oogoniol-I, -2 and -3 , steroidal sex hormones of the water mould, Achlya. Journal of the American Chemical Society 97, 2544-2545.

Mortimer, A. M. \& SHAw, D.S. (I975). Cytofluorimetric evidence for meiosis in gametangial nuclei of Phytophthora drechsleri. Genetical Research 25, 201-205.

Popplestone, C. R. \& UnRAU, A. M. (1974). Studies on the biosynthesis of antheridiol. Canadian Journal of Chemistry 52, 462-468.

RAPER, J. R. (1940). Sexual hormones in Achlya. II. American Journal of Botany 27, I62-I 73.

Rottem, S., PfEndt, E. A. \& HAyflick, L. (I97I). Sterol requirements of T-strain mycoplasmas. Journal of Bacteriology ro5, 323-330.

SAnsome, E. (1961). Meiosis in the oogonium and antheridium of Pythium debaryanum Hesse. Nature, London I91, 827-828.

Sansome, E. (1965). Meiosis in diploid and polyploid sex organs of Phytophthora and Achlya. Cytologia $3^{\mathbf{0}}$, $103-I I 7$.

SAnsome, E. \& Brasier, C. M. (1973). Diploidy and chromosomal structural hybridity in Phytophthora infestans. Nature, London 24I, 344-345.

Shaw, D. S. \& KHAKI, I. A. (I971). Genetical evidence for diploidy in Phytophthora. Genetical Research $\mathbf{7}$, I $65-167$.

SмIтH, P. F. (I 964). Relation of sterol structure to utilization in pleuropneumonia-like organisms. Journal of Lipid Research 5, $12 \mathrm{I}-125$.

SMITH, P. F. \& LYNN, R. J. (1958). Lipid requirements for the growth of pleuropneumonia-like organisms. Journal of Bacteriology 76, 264-269. 